\title{
Through the looking glass: Avoiding a retrospective approach to new technology acquisition
}

\author{
Alan M. Speir, MD
}

\author{
From the Department of Cardiac Surgery, Inova Heart and Vascular Institute, Falls Church, Va. \\ Disclosures: Author has nothing to disclose with regard to commercial support. \\ Received for publication Oct 25, 2017; accepted for publication Oct 28, 2017; available ahead of print Dec 2, \\ 2017. \\ Address for reprints: Alan M. Speir, MD, Department of Cardiac Surgery, Inova Heart and Vascular Surgery, 3300 \\ Gallows Rd, Falls Church, VA 22042 (E-mail: aspeir1@gmail.com). \\ J Thorac Cardiovasc Surg 2018;155:681 \\ 0022-5223/\$36.00 \\ Copyright (C) 2017 by The American Association for Thoracic Surgery \\ https://doi.org/10.1016/j.jtcvs.2017.10.117
}

In Through the Looking-Glass, Lewis Carroll, a pseudonym for an Anglican deacon who taught mathematics at Oxford University, writes about the imaginary, backward world on the other side of Alice's mirror, or looking-glass. Similarly, Engelman and colleagues ${ }^{1}$ describe the current state of technology acquisition as backward when compared with previous acquisition systems.

For many years, cardiothoracic surgeons were regarded as experts at the forefront of the evaluation and procurement of new cardiothoracic devices or products. After a surgeon identified a new technology, clinical effectiveness, appropriateness criteria, and cost analytics were applied and consideration was given to a surgeon's preferences. Such autonomy by surgeons was well deserved. Who was more knowledgeable or could understand the implications for improved patient care than the surgeons who were going to apply the new technology?

Engelman and colleagues ${ }^{1}$ describe the hospital acquisition process as having been relegated to value analysis committees (VACs). VACs are charged with "improving patient care and controlling product costs with an emphasis on the purchase and utilization of cost-effective, high-quality products through an approved process of determining clinical efficacy and product evaluation." Further, they describe the role that "has emerged as reimbursement rates dropped, uncompensated care rose, and thin hospital margins narrowed, necessitating a means to control rising health care costs." 1 The central theme is cost reduction, which may not be associated with high quality. It is not difficult to follow or understand this evolution, because surgeons may have preference for a particular device, whereas the health system is dealing with the same manufacturer for multiple technologies.

Regardless of the rationale, surgeons have been relegated to an arm's-length relationship with the acquisition of technology. This is a further example of the decline in autonomy of cardiothoracic surgeons in health care models that have

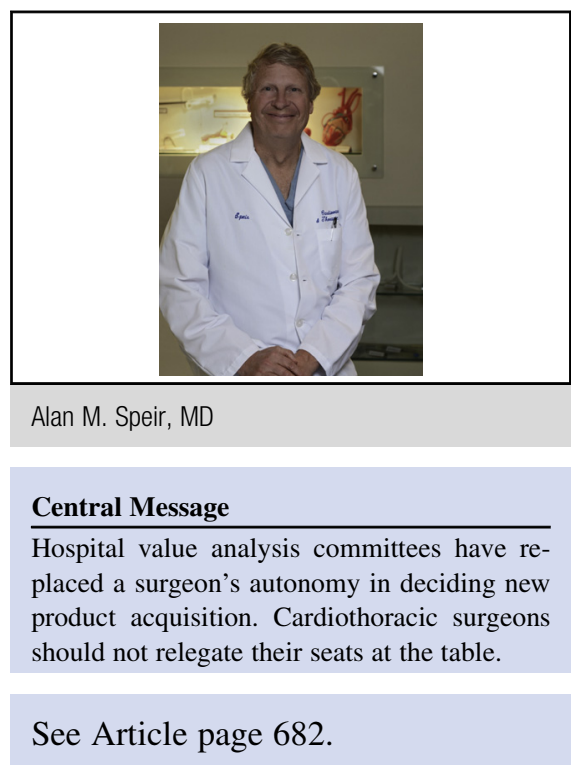

been experiencing dynamic change over the past several years. O'Connor and Lanning ${ }^{2}$ make the observation that "of the many characteristics that classify the practice of medicine as a profession, autonomy plays the most important role." Commonly, surgeons are now practicing within an employment model (personal communication with Frank L. Fazzalari, chairman, Society of Thoracic Surgeons Workforce on Practice Management) and have sacrificed independence and autonomy for the hope of more secure compensation.

Despite the high-level recommendations for process improvement within VACs, Engelman and colleagues ${ }^{1}$ could have provided more practical methods that could define the value conferred by often more costly products. A specific structure and surgeon involvement in VACs would address concerns over erosion of autonomy.

A look backward, although tempting, is neither practical nor realistic in the health care delivery systems that have become the new normal. We can, however, continue to press forward for involvement in these processes with a focus on maintaining our autonomy and continued presence in the decision process.

\section{References}

1. Engelman DT, Boyle EM, Benjamin EM. Addressing the imperative to evolve the hospital new product value analysis process. J Thorac Cardiovasc Surg. 2018;155: $682-5$

2. O'Connor SJ, Lanning JA. The end of autonomy? Reflections on the postprofessional physician. Health Care Mgmt Rev. 1992;17:63-72. 